Mini Review

\title{
Impact of cancer diagnosis on emotional well-being and quality of life on LGBT population in India and across Europe;A report drawn on the bases of experience and bird's eye view of a psycho- oncologist
}

\begin{abstract}
Diagnosis of cancer indeed brings detrimental psycho-social implications on general wellbeing and quality of life of the people, however, when the person on the receiving end belongs to a minority or vulnerable group, its impact is not only multiplied, but may extend in numerous parameters of personal, social, and professional life. This report focuses on emotional impact of cancer diagnosis on people belonging to LGBT community and its implications on their Quality of Life. Besides, this report also tries to explain the significant challenges faced by clinicians in India and across the Europe, while offering their best care in a highly sensitive situation, in terms of respecting confidentiality, integrity, and secrecy of sexual orientation, particularly in conservative societies like India.

For this report, the author has evaluated the documented case reports, from the year 2014 till the year 2020, combined with literature review and tool of his experience in the field. Besides, this report draws some comparisons between the LGBT cancer patients in India and Europe (mostly Belgium) and offers professionals and clinician's sensibility to possibly design tailormade interventions when encountering this vulnerable, yet highly specialized group. This entire report is based on the author's clinical experience in psycho-oncology over a course of 8 years in the field.
\end{abstract}

Keywords: LGBT cancer, psycho-oncology, clinical experience, LGBT community, online friends
Volume II Issue 6 - 2020

\author{
Irfan M Lone \\ Owner \& founder Conscious 'Connections, Co-founder \& \\ coordinator Lymphoma Support Group India, Belgium
}

\begin{abstract}
Correspondence: Irfan M Lone, M.Phil. Psycho-Oncology, Master's In Psychology, Owner \& founder Conscious 'Connections, Co-founder \& coordinator Lymphoma Support Group India, Hollandstraat 24, Antwerpen 2060, 24, Hollandstraat, Antwerpen 2060, Belgium, Tel 048421 7025, Email irfanmlone@outlook.com
\end{abstract}

Received: November 19, 2020 | Published: December 28, 2020

\section{Introduction}

In order to draw significant comparisons between the disparities in dealing with LGBT cancer patients in East and West, it becomes extremely essential for us, as clinicians and health care providers to understand the bigger picture of the LGBT community in general. As we all know that in India, we still have not been able to reach a point where all the people are accepted unconditionally; and when it comes to sexual orientation in particular, we still face old taboos, sociocultural and religious pressures, prejudice, and judgments. Moreover, while dealing with clients belonging to the LGBT community, clinicians also doesn't have it easy. In India, we still do not approve same-sex marriages and the rights of the LGBT community are still not fully recognized, which puts this group on the lines of extreme vulnerability, both emotional and otherwise. On the other hand, the acceptance from family and friends, the government, and the general public and endless fear of ending up alone all life, makes things worse. However, thankfully, the younger generation in India seems to be more accepting, possibly due to social media explosion from last decade, or possibly due to easy access to worldwide web, smart phones, and so on, and therefore, cultural and ideological exchanges with "online friends" virtual friends living abroad in various corners of the globe, and off course, also to some extent, due to changing norms in Indian cinema.

\section{Method}

For this report, patients' case records were analyzed from the year 2014 till the year 2020, in combination with literature review and the author's experience in the field of psycho-oncology. Then the comparisons were made in terms of Indian LGBT patients and the patients in Europe (Mostly Belgium). Clinical difficulties experienced during some of the therapy encountered by the author were pointed down. References of difficulties and challenges faced by patients were taken from the literature review, and the report summery was formulated.

\section{Discussion}

If we look at the other side of the world, the west, specifically in Europe many countries give full rights and acknowledgments to all the individuals belonging to the LGBT group; they can get married, have children or adopt children and possess properties, dress the way they want to, organize and participate in prides as a way of expressing and celebrating gender and sexual freedom, be open and free and take pride in their sexual orientations, have equal opportunity in the job market and thus enjoy normal married and committed life and so on. But this doesn't mean that they don't face challenges here. This community faces unique challenges here as well, sometimes more serious than anywhere else, but in the long run, these challenges are mostly practical and in most of the cases tangible and thus resolvable; besides the support from the government and political system and therefore society as a whole makes the situations and scenarios different here..$^{1-5}$

Both in India or west, any gay, lesbian, or anyone belonging to the LGBT community, after hearing "The Bad News of BIG C" experience the same emotions and shock waves, however as far as 
my experience in India goes, Indian patients feel these emotions to more extreme levels and their implications are highly significant. Fear of getting the sexual orientation disclosed after the diagnosis, fear of being judged by clinicians, and in extreme cases fear of being disowned by family and caregivers are the primary apprehensions or stressors that can profoundly impact the mental well-being and thus the quality of life of such patients. ${ }^{6,7}$ In some case, I have also seen that these fears significantly impact the decision-making process about cancer treatment and therapies, (in such cases, the patients let treating oncologists decide for them, "because if it helps to protect my sexual orientation, it works for me, moreover doctors are the experts to decide for my treatment").

My experience in the field of psycho-oncology in India and also the great opportunity to work in South -East Asia's biggest cancer hospital, I have had multiple clients, who were not out to their families, but due to cancer diagnosis, there were situations when they had to break the secret of their sexual orientation, which was most of the times very difficult for me as a clinician to deal with; given the fact that my role was highly essential in treatment process, I should make sure that family is in peace with this truth and accepts the patient as he/she is. The other side of the coin of clinical/professional difficulty was that this truth should only be only reviled to a psycho-oncologist/ psychologist (in this case me), other than the family (mostly father and mother). In most of the cases, even siblings should not know about this truth. Sexual orientation should not be disclosed in any way with the rest of the treating team, absolutely no body. The therapies with patient and family would sometimes last for months, irrespective of socio-economic status, or education or other demographics of the family. Now for the family, there were two types of catastrophes to deal with, the BIG ' $\mathrm{C}$ ' and the Orientation of their child. But in most of the cases both the parties would come to a peaceful acceptance. ${ }^{8-10}$ Because "saving lives and treating cancer is most essential and therefore priority at that moment. "Sexual orientation can be dealt with later, "Because I know few of the Baba Jis, (spiritual saints in India) they can surely help us". These are the words of a father of 24-year-old Rectum cancer Namit, who said that he needs to disclose the orientation before he gets started with cancer treatment. Namit was studying for aviation and was an aspiring Pilot, had a long term 4-year stable relationship with a guy called (Amar). Both the families didn't know about the sexual orientations of their sons, yet Namit came out to his family after 3 weeks of knowing his cancer diagnosis. Unfortunately, Namit passed away after 15 months of his diagnosis, the disease was already in metastasis and it didn't respond to any sort of therapy. The last months and weeks were hard for Namit and the family. (The names of the persons have been changed for professional confidentiality)

On the other hand, however, in Belgium for example, LGBT people are very open, as I discussed before, have an equal position and opportunities in society. The issues and stressors are completely different and unique than in India, however, the basic issues are the same for any cancer patient, when he/she gets to know about the cancer diagnosis, but here the fundamental basic issues revolve round work, relationship, and logistics, which are more tangible or practical, if we look at them in-depth and with a logical eye, which doesn't in any way mean that the shock waves and disbelief is not experienced here by this group. The primary emotional issues in Belgium according to my experience however are;

a. If the relationship or commitment or partnership will continue after cancer diagnosis. b. Identifying and accepting the role changes in relationship (from a partner, lover or husband and so on to care-giver)

c. Managing Logistics, for example with work, hospital visits and family life.

d. Body image issues among younger patients (the younger the patient, the stronger the intensity)

e. Negative implications on dating and sexual behaviors after diagnosis

\section{f. Disparities in self-image}

However, after the treatment gets started, gradually the information and knowledge of cancer diagnosis, treatment, and prognosis (prognosis, mostly in European patients, because in the east, specifically in India, patients are not yet told about clear prognosis, especially when prognosis is poor but it has improved over the past decade) sink in and these issues come to peace, which I have experienced and observed with Indian counterparts, lasts even longer and in most of the case go along the whole trajectory of the cancer journey and sometimes even after treatment. ${ }^{11}$

To a great extent, the solutions to these fundamental issues are directly correlated to the quality of caregiving and social support. The diagnosis of cancer also brings a great deal of challenges in the family stricture, dynamics, and "Normalcy." Given the fact that caregiving can be a delightful gift one can offer to change the picture of the cancer journey; on the other hand, it can be extremely irritating and can profoundly impact the quality of life of the caregiver. Burnout, verbal assault, irregularities in professional and social life, mood disorders, chronic and acute stress, and fatigue are the basic issues reported globally by caregivers, irrespective of cultural or religious backgrounds. In India, the primary caregivers are family (Parents) and is seen more structured and organized when it comes to caring for LGBT patient, but in Europe (Belgium) the primary caregiving is offered by partner or lover or husband/wife (if the patient is committed, legal partnership or married) family and friends follow the line. But if the patient is single due to any reason, primary caregiving is provided by family (including parents and siblings), followed by friends. In Belgium, both heterosexual and the LGBT cancer patients enjoy their social lives, even during the treatment of cancer, and thus going out, meeting friends and family, organizing small feasts, and so on doesn't make them feel that they need care all the time, which on the other hand in India, patients are mostly forbidden to go out in gatherings and thus are confined to home or in hospital, which makes them feel and believe that they are sick, thus need care all the time. This, in turn, puts the caregivers in India generally on a spectrum of unique challenges ranging from mood disorders, fatigue to clinical depression. ${ }^{12-14}$

Psychologists and Psycho-oncologists need to be extremely empathetic and possess a non-judgmental attitude, especially in India. Clients belonging to this community must feel safe and secure, to first bring the issues about sexual orientation on the table and secondly, to feel a sense of deep trust and respect with a psychologist to resolve challenges concerning orientation along-side the cancer therapies. Such cases should not be considered as "glittering and rainbow disco lights decorating the ceilings" (by this, I mean a psychologist should never highlight in their professional profile, with laughter, pride and fun that these cases were or are being dealt by him/her). But this doesn't mean that such cases should be regarded as special ones, rather they should be considered highly sensitive and extremely confidential. ${ }^{15,16}$ 
Indeed, Special education focusing on LGBT and cancer could certainly uplift the sensitivity of such cases, make clinicians more aware of this group of patients, and likewise make them more confident and practical in dealing with such patients. Other clinical professionals including, nurses and oncologists along with primary caregivers, families, and close ones could also be sensitized over this subject, which in turn will ultimately reflect that "we do not discriminate them in health care and we do our best to take care of them as One Clinical Team".

Some of the common issues reported by LGBT survivors after the completion of cancer treatment in no particular order in Belgium are:

a. Long-term psychological Distress with or without comorbid another DSM diagnosis

b. Depression and loneliness

c. High intensity of Body Image Issues

d. Uncertainty in existing relationships or starting a new serious committed relationship.

e. Intense feelings of physical and sexual undesirability

f. Apprehension to openly participate in dating behaviors

g. Inconsistency with job profiles.

(The above-mentioned issues go in line with Indian context, which gives me an impression that these issues are at the core in every society when we focus on LGBT and cancer as a whole)

There is a lot to offer in terms of breaking the stigma about LGBT and cancer, however, I feel it falls in the broader and huge domain of Sexual Orientation and socio-cultural and religious norms and belief systems in India or any society in general. Yet on the other hand, as Clinicians and oncology professionals we form a big group together and if we, as a big group open our hearts and hands to serve and care for them with compassion, that would be already a great start and the legacy would be build up in our professionalism, and possibly other professionals will be inspired and they will also follow the steps and ultimately, we will create a society where everyone is loved, respected and given ultimate care they deserve, irrespective of caste, color, religion or ORIENTATION.

\section{Conclusion}

The impact of cancer diagnosis is indeed on almost every aspect on the lives of people belonging to this group. To confront the challenges faced during clinical practices, health care practitioners need to start exploring the area in more detail and to formulate some special guidelines for handling and care for this special. Besides, in order to provide an optimum care, a multi-disciplinary approach is essentially needed in terms of formulating new guidelines and protocols for care and treatment. This will ultimately create a sound clinical task force and will also empower the patients throughout their cancer journey.

"If cancer never discriminates, why should we as clinicians do so, let's pledge to defeat cancer with love and compassion."

\section{Acknowledgments}

None.

\section{Conflicts of interest}

The author declares there are no conflicts of interest.

\section{Funding}

None.

\section{References}

1. Wandrekar J, Nigudkar A. What Do We Know About LGBTQIA+ Mental Health in India? A Review of Research From 2009 to 2019. Journal of Psychosexual Health. 2020;2(1):26-36.

2. Kamen C. Lesbian, Gay, Bisexual, and Transgender (LGBT) Survivorship. Semin Oncol Nurs. 2018;34(1):52-59.

3. Johar, Navtej Singh, V Ors. Union of India. Writ Petition (Criminal) No. 76 of 2016, Supreme court of India. 2019.

4. Kamen C, Mustian KM, Dozier A, et al. Disparities in psychological distress impacting lesbian, gay, bisexual and transgender cancer survivors. Psychooncology. 2015;24(11):1384-1391.

5. Wight RG, Leblanc AJ, Lee Badgett MV. Same-sex legal marriage and psychological well-being: findings from the California Health Interview Survey. Am J Public Health. 2013;103(2):339-346.

6. King M, Semlyen J, Tai SS, et al. A systematic review of mental disorder, suicide, and deliberate self-harm in lesbian, gay and bisexual people. BMC Psychiatry. 2008;8:70

7. Sharma AJ, Subramanyam MA. Psychological wellbeing of middleaged and older queer men in India: A mixed-methods approach. PLoS One. 2020;15(3):e229893.

8. Cloyes KG, Hull W, Davis A. Palliative and End-of-Life Care for Lesbian, Gay, Bisexual, and Transgender (LGBT) Cancer Patients and Their Caregivers. Semin Oncol Nurs. 2018;34(1):60-71.

9. Kealy-Bateman W. The possible role of the psychiatrist: the lesbian, gay, bisexual, and transgender population in India. Indian J Psychiatry. 2018;60(4):489-493.

10. Sharma H. Are we being trained to discriminate? Need to sensitize doctors in India on issues of gender and sexuality. RHiME. 2018;5:3543.

11. Skerrett DM, Kõlves K, De Leo D. Suicides among lesbian, gay, bisexual, and transgender populations in Australia: an analysis of the Queensland Suicide Register. Asia Pac Psychiatry. 2014;6(4):440-446.

12. Sawant NS. Transgender: status in India. Ann Indian Psychiatry. 2017;1(2):59-61.

13. Zeeman L, Sherriff N, Browne K, et al. A review of lesbian, gay, bisexual, trans and intersex (LGBTI) health and healthcare inequalities. Eur J Public Health. 2019;29(5):974-980.

14. Elwood WN, Irvin VL, Sun Q, et al. Measuring the influence of legally recognized partnerships on the health and well-being of same-sex couples: utility of the california health interview survey. LGBT Health. 2017;4(2):153-160

15. Fish J. Williamson I. Exploring lesbian, gay and bisexual patients' accounts of their experiences of cancer care in the UK. Eur J Cancer Care 2016;10:1-13.

16. Whitehead J, Shaver J, Stephenson R. Outness, Stigma, and Primary Health Care Utilization among Rural LGBT Populations. PLoS ONE. 2016;11:1-17 